Clinical research

\title{
Assessment of fatigue in patients with a permanent cardiac pacemaker: prevalence and associated factors
}

Maria Polikandrioti ${ }^{1}$, Konstantinos Tzirogiannis ${ }^{2}$, Sofia Zyga ${ }^{3}$, Georgia Gerogianni ${ }^{1}$, Spyridoula Stefanidou ${ }^{1}$, Athanasia Tsami ${ }^{4}$, Georgios Panoutsopoulos ${ }^{2}$

\begin{abstract}
${ }^{1}$ Department of Nursing, University of West Attica, Athens, Greece ${ }^{2}$ Laboratory of Physiology and Pharmacology, Department of Nursing, Faculty of Human Movement and Quality of Life Sciences, University of Peloponnese, Sparta Lakonias, Greece

${ }^{3}$ Department of Nursing, Faculty of Human Movement and Quality of Life Sciences, University of Peloponnese, Sparta Lakonias, Greece

"University General Hospital of Athens “Laiko", Athens, Greece
\end{abstract}

Submitted: 9 August 2018

Accepted: 11 December 2018

Arch Med Sci Atheroscler Dis 2018; 3: e166-e173

DOI: https://doi.org/10.5114/amsad.2018.81085

Copyright @ 2018 Termedia \& Banach

\begin{abstract}
Introduction: Fatigue is a debilitating symptom of subjective nature which lacks effective therapy. The aim of the study was to assess levels of fatigue and the associated factors among patients with permanent cardiac pacemaker (PCM).

Material and methods: This was a cross-sectional study carried out in Athens. The study sample consisted of 250 patients with a PCM.

Results: Data indicated moderate to low levels of fatigue. Furthermore, women (median: 24, $p=0.001$ ), those with primary school education (median: $21, p=0.001)$, those who were "a little-not at all" informed about PCM (median: 31, $p=0.001$ ), those who had someone to help them in daily activities (median: $23, p=0.001$ ), those who did not believe that PCM solved their cardiac problem (median: $36, p=0.001$ ), and those who did not believe that their quality of life was improved (median: $35, p=0.001$ ) had high levels of fatigue. Moreover, high levels of fatigue were felt by those who characterized themselves as anxious and those who reported to be very anxious about their heart rate and the proper function of PCM (medians: 21.5, 25 and 25 respectively). Additionally, more fatigue was felt by participants who did not smoke after implantation and did not exercise at all (medians: 20 and 24 respectively). Finally, older patients felt more fatigue (rho $=0.248$ ) while the later the implantation device was inserted the more fatigue the patients felt ( $r$ o $=0.274)$.

Conclusions: The present results will help clinicians to acquire an in-depth knowledge of factors associated with fatigue after implantation.
\end{abstract}

Key words: fatigue, pacemaker, implanted device.

\section{Introduction}

Permanent cardiac pacemakers (PCM) are small implanted electronic devices that treat chronic cardiac rhythm dysfunction. Ever since the first cardiac pacing device was implanted in 1958 by Dr Ake Senning, the rate of implantation has been continually increasing [1] According to estimates, 2.9 million patients received permanent pacemakers in the United States between 1993 and 2009 [2]. The most common type

\author{
Corresponding author: \\ Prof. Maria Polikandrioti \\ Department of Nursing \\ University of West Attica \\ 28 Spyridon St \\ 12242 Athens, Greece \\ Phone: +3316972425054 \\ E-mail: mpolik2006@yahoo. \\ com
}


of permanent pacemaker is dual-chamber where two leads are implanted, one in the right ventricle and one in the right atrium (PMs-DDD) [1]. Other types include single-ventricular (VVI), single-atrial (AAI), and biventricular (BiV) devices [2].

This invasive procedure is frequently accompanied by several long- or short-term complications $[3,4]$. Early complications occur in up to $4-5 \%$ of cases while late complications reach $2.7 \%$ [1, 3]. Complications are mainly attributed either to procedure related factors (hematoma, lead dislodgement, lack of antibiotic prophylaxis, etc.) or to device related characteristics (abdominal pocket, epicardial leads, etc.) [4-6].

Complication rates seem to vary globally due to several difficulties in identifying and recording them as well as to differences in methodology. Other important considerations after device implantation include patient's clinical status, battery life, pulse width, sensing function, and lead integrity [4-7].

Fatigue is a common symptom in chronic illness; however, it is not revealed by physical examination or laboratory and diagnostic tests, thus remaining a mentally and physically debilitating syndrome if it is untreated $[8,9]$.

It is well known that pacemaker implantation demands life long therapy. Therefore, the frequency and method of clinic follow-up should be scheduled before hospital discharge and revised according to the needs of each patient or the device. During regular cardiac device monitoring, it is essential to obtain elaborate information about fatigue along with other patients' needs such as accessibility to medical care, family and social support, cardiovascular or medical problems, and several others [4-7].

To the best of our knowledge, fatigue has scarcely been a subject of enquiry prior and post-operatively or in clinical follow-up and pacemaker control. Additionally, there is limited evidence on the multidisciplinary therapeutic approach for the fatigued recipient.

Thus, this cross-sectional study was carried out to explore the levels of fatigue in patients with a permanent cardiac pacemaker and the associated factors.

\section{Material and methods}

\section{Study population}

The sample of the study consisted of 250 patients who had a permanent cardiac pacemaker (160 men and 90 women). This sample was a convenience sample.

Criteria for inclusion in the study were: a) patients to have undergone implantation of a permanent cardiac pacemaker and b) patients to have the ability to write and read the Greek language fluently. Regarding the type of cardiac pacemaker, participants had: a) a single chamber system (VVI) and b) a dual chamber system (DDD).

The exclusion criteria were: a) patients with a history of mental illness and b) patients with a chronic disease.

\section{Data variables}

Data collection was performed via an interview using a questionnaire developed by the researchers so as to fully serve the purposes of the study. Data collection lasted approximately $15 \mathrm{~min}$ and took place when patients were waiting for their regular follow-up in the outpatient department of two public hospitals in Attica. The research lasted from January 2017 to August 2017.

The data collected for each patient included: demographic characteristics (e.g. gender, age, education level, etc.), clinical characteristics (e.g. age of implantation, type of pacemaker, etc.), therapy characteristics (e.g., adherence to treatment guidelines, etc.), and other characteristics as reported by patients.

Ethical considerations: The study was approved by the Medical Research Ethics Committee of each hospital that took part in this study and it was conducted in accordance with the Declaration of Helsinki (1989) of the World Medical Association.

All patients participated in the study voluntarily and had their anonymity preserved. Written informed consent was obtained from all patients being interviewed.

\section{Assessment of fatigue}

The fatigue of participants was evaluated by the Greek version of the Fatigue Assessment Scale (FAS). The scale collects information related to perceived fatigue and has an internal consistency equal to 0.761 (Cronbach's $\alpha$ coefficient). The scale consists of 10 questions that assess the fatigue of patients on a Likert type scale (scores from 1 to 5). The coding of responses is as follows: 1 = never, 2 = sometimes, 3 = regularly, $4=$ often, 5 = always. Therefore, the total score of the questionnaire ranged between 10 and 50. Five questions are related to physical fatigue and the other five to mental fatigue. The score is summed up separately for the questions that assess physical fatigue, and separately for those that assess mental fatigue. Afterwards, both scores were added together to represent the total fatigue score. Higher values of scores indicate increased fatigue [10].

\section{Statistical analysis}

Categorical data are presented in absolute and relative (\%) frequencies, whereas continuous data are presented with median (interquartile 
range). The Kruskal-Wallis test was used to test the existence of an association between fatigue and a factor with more than two categories, while the Mann-Whitney test was used to test for the existence of an association between fatigue and a factor with two categories. Spearman's rho correlation coefficient was used to evaluate the association between fatigue and continuous patient characteristics. The level of statistical significance was set to $\alpha=5 \%$. All statistical analyses were performed using the SPSS version 20 package.

\section{Results}

\section{Sample description}

According to the descriptive results, men accounted for $64 \%$ of the sample, half of the sample was over 71 years of age (median) and 48\% had primary school education. Regarding the type of pacemaker, $32 \%$ had a single chamber system (VVI) and 68\% had dual chamber system (DDD). In $50 \%$ of participants, the pacemaker had been placed under the age of 66 (median).

In terms of information, $46.8 \%$ and $34.8 \%$ reported they were "sufficiently" and "well" informed, respectively while $41.2 \%$ believed that having an information sheet regarding the pacemaker was necessary.

Moreover, $78 \%$ stated that they regularly attended their device follow-up, and $78.8 \%$ reported adhering to anti-arrhythmic treatment. In regard of complications after implantation, skin infection occurred in $8.9 \%$ of the patients.

The majority of the patients reported to have very good relations with medical and nursing staff (82.8\%). Furthermore, 69.6\% characterized themselves as anxious, while $23.2 \%$ and $19.6 \%$ of participants were very anxious about their heart rate and the proper function of the implanted device, respectively.

Table I. Patients' demographics $(n=250)$

\begin{tabular}{|lc|}
\hline Parameter & $\begin{array}{c}\text { Value } \\
N(\%) \text { or } \\
\text { median (IQR) }\end{array}$ \\
\hline Gender (male) & $160(64.0)$ \\
\hline Education: & $120(48.0)$ \\
\hline Primary school & $80(32.0)$ \\
\hline Secondary school & $29(11.6)$ \\
\hline University & $20(8.0)$ \\
\hline MSc-PhD & $1(0.4)$ \\
\hline No education & $71(59-78)$ \\
\hline Age [years] & $66(56-73)$ \\
\hline Age when pacemaker was placed & \\
\hline
\end{tabular}

Half of the patients had someone else to help them with their daily activities (52.4\%) while $32.0 \%$ fulfilled their social and family responsibilities. Almost all the participants believed that the pacemaker solves the problem of arrhythmia (94.8\%) and $50.8 \%$ stated that their quality of life was much improved.

Concerning their habits after implantation, $17.6 \%$ of recipients continued smoking, $85.3 \%$ consumed alcohol occasionally and $44.4 \%$ did not exercise at all. Additionally, $49.8 \%$ had not reduced the usage of a mobile phone, $88.4 \%$ knew they had to carry a device identification card (ID card) and $74.8 \%$ "always" carried this special card (Tables I- III).

\section{Fatigue}

As far as fatigue in concerned, it was observed that at least $50 \%$ of the patients' scores were below 19 (median) in the total score and below

Table II. Patients' clinical characteristics $(n=250)$

\begin{tabular}{|c|c|}
\hline Variable & $N(\%)$ \\
\hline \multicolumn{2}{|l|}{ Type of pacemaker: } \\
\hline VVI single chamber system & $80(32)$ \\
\hline DDD dual chamber system & $170(68.0)$ \\
\hline \multicolumn{2}{|c|}{$\begin{array}{l}\text { How well are you informed about the implanted } \\
\text { device? }\end{array}$} \\
\hline Very & $87(34.8)$ \\
\hline Sufficiently & $117(46.8)$ \\
\hline A little & $42(16.8)$ \\
\hline Not at all & $4(1.6)$ \\
\hline \multicolumn{2}{|c|}{$\begin{array}{l}\text { Do you believe an information sheet regarding the } \\
\text { pacemaker is necessary? }\end{array}$} \\
\hline Very & $103(41.2)$ \\
\hline Moderately & $97(38.8)$ \\
\hline A little & 49 (19.6) \\
\hline Not at all & $1(0.4)$ \\
\hline \multicolumn{2}{|c|}{ Do you attend the regular device follow-up? } \\
\hline Regularly & $195(78.0)$ \\
\hline Sufficiently & $53(21.2)$ \\
\hline A little & $1(0.4)$ \\
\hline Not at all & $1(0.4)$ \\
\hline \multicolumn{2}{|c|}{ Do you adhere to your antiarrhythmic treatment? } \\
\hline Closely & $197(78.8)$ \\
\hline Sufficiently & $50(20.0)$ \\
\hline A little & $2(0.8)$ \\
\hline Not at all & $1(0.4)$ \\
\hline
\end{tabular}


Table III. Other patients' characteristics $(n=250)$

\begin{tabular}{|c|c|}
\hline Variable & $N(\%)$ \\
\hline \multicolumn{2}{|l|}{ Relation with medical and nursing staff: } \\
\hline Very good & $207(82.8)$ \\
\hline Good & $41(16.4)$ \\
\hline Moderate & $2(0.8)$ \\
\hline Do you consider yourself anxious? (Yes) & $174(69.6)$ \\
\hline \multicolumn{2}{|c|}{ Do you have anxiety about your heart rate disorder? } \\
\hline Very much & $58(23.2)$ \\
\hline Quite a lot & $47(18.8)$ \\
\hline A little & $65(26.0)$ \\
\hline Not at all & $80(32.0)$ \\
\hline \multicolumn{2}{|c|}{$\begin{array}{l}\text { Do you have anxiety about the proper function of the } \\
\text { implanted device? }\end{array}$} \\
\hline Very much & $49(19.6)$ \\
\hline Quite a lot & $52(20.8)$ \\
\hline A little & $61(24.4)$ \\
\hline Not at all & $88(35.2)$ \\
\hline $\begin{array}{l}\text { Do you have someone who helps you } \\
\text { in your everyday activities? (Yes) }\end{array}$ & $131(52.4)$ \\
\hline \multicolumn{2}{|c|}{$\begin{array}{l}\text { Do you fulfill your social and family responsibilities, } \\
\text { after device implantation? }\end{array}$} \\
\hline Fully & $80(32.0)$ \\
\hline Sufficiently & $115(46.0)$ \\
\hline A little & $51(20.4)$ \\
\hline Not at all & $4(1.6)$ \\
\hline $\begin{array}{l}\text { Do you think that the pacemaker } \\
\text { solves the problem of arrhythmia? (Yes) }\end{array}$ & $237(94.8)$ \\
\hline \multicolumn{2}{|c|}{$\begin{array}{l}\text { Has your quality of life improved after device } \\
\text { implantation? }\end{array}$} \\
\hline Very much & $127(50.8)$ \\
\hline Sufficiently & $99(39.6)$ \\
\hline A little & $23(9.2)$ \\
\hline Not at all & $1(0.4)$ \\
\hline \multicolumn{2}{|l|}{ Have you reduced mobile phone usage? } \\
\hline Greatly & $2(0.9)$ \\
\hline Sufficiently & $35(16.6)$ \\
\hline A little & $69(32.7)$ \\
\hline Not at all & $105(49.8)$ \\
\hline $\begin{array}{l}\text { Do you smoke after device } \\
\text { implantation? (Yes) }\end{array}$ & $44(17.6)$ \\
\hline $\begin{array}{l}\text { Do you consume alcohol after device } \\
\text { implantation? (Yes) }\end{array}$ & $71(28.5)$ \\
\hline Every day & $5(7.4)$ \\
\hline
\end{tabular}

\begin{tabular}{|c|c|}
\hline Variable & $N(\%)$ \\
\hline 1-2 times per week & $5(7.4)$ \\
\hline Occasionally & $58(85.3)$ \\
\hline \multicolumn{2}{|c|}{ Do you exercise after device implantation? } \\
\hline Very much & $13(5.2)$ \\
\hline Sufficiently & $41(16.4)$ \\
\hline A little & $85(34.0)$ \\
\hline Not at all & $111(44.4)$ \\
\hline $\begin{array}{l}\text { Do you know that you have to carry } \\
\text { your identification card? (Yes) } \\
\text { (card with your pacemaker info and } \\
\text { personal data) }\end{array}$ & $221(88.4)$ \\
\hline \multicolumn{2}{|c|}{ Do you always have this special card with you? } \\
\hline Yes & $187(74.8)$ \\
\hline No & $39(15.6)$ \\
\hline Sometimes & $24(9.6)$ \\
\hline
\end{tabular}

15 and 4 as regards physical and mental fatigue, respectively (Table IV). Regarding the total score, it was found that $25 \%$ of the participants had a score higher than 26. Accordingly, with regard to physical and mental fatigue, $25 \%$ of enrolled patients had a score higher than 20 and 8 , respectively. These values indicate moderate to low levels of fatigue.

\section{Characteristics associated with fatigue}

Table $\mathrm{V}$ presents the statistically significant associations between patients' characteristics and fatigue. More specifically, statistically significantly higher fatigue was felt by women (median: $24, p=$ 0.001 ), those with primary school education (median: $21, p=0.001)$, those who were "a little or not at all" informed about the implanted device (median: $31, p=0.001$ ), those who considered themselves anxious or were very anxious about their heart rate or the proper function of their device (medians: $21.5,25$ and 25 respectively), those who had someone helping them in their everyday activities (median: 23, $p=0.001$ ), those who did not believe that the pacemaker solves the problem of arrhythmia (median: 36, $p=0.001$ ) and those who did not

Table IV. Fatigue score

\begin{tabular}{|lc|}
\hline Variable & Median (IQR) \\
\hline Total score of fatigue (range: 10-50) & $19(15-26)$ \\
\hline Physical fatigue (range: 7-35) & $15(11-20)$ \\
\hline Mental fatigue (range: $3-15)$ & $4(3-8)$ \\
\hline
\end{tabular}


Table V. Characteristics associated with fatigue

\begin{tabular}{|c|c|c|c|c|c|c|}
\hline Parameter & $\begin{array}{l}\text { Total Fatigue } \\
\text { Median (IQR) }\end{array}$ & $P$-value & $\begin{array}{l}\text { Physical Fatigue } \\
\text { Median (IQR) }\end{array}$ & $P$-value & $\begin{array}{l}\text { Mental Fatigue } \\
\text { Median (IQR) }\end{array}$ & $P$-value \\
\hline Gender: & & 0.001 & & 0.001 & & 0.001 \\
\hline Male & $18(14-23)$ & & $14(11-18)$ & & $3(3-6)$ & \\
\hline Female & $24(18-29)$ & & $18(14-21)$ & & $6(4-8)$ & \\
\hline Education: & & 0.001 & & 0.001 & & 0.001 \\
\hline Primary school & $21(17-29)$ & & $16(13-21)$ & & $5(3-8)$ & \\
\hline Secondary school & $19(15-27)$ & & $16(12-20)$ & & $4(3-8)$ & \\
\hline University & $15(13-18)$ & & $12(9-15)$ & & $3(3-4)$ & \\
\hline $\begin{array}{l}\text { Level of information about the } \\
\text { implanted device: }\end{array}$ & & 0.001 & & 0.001 & & 0.001 \\
\hline Very well & $18(13-24)$ & & $14(10-17)$ & & $3(3-7)$ & \\
\hline Enough & $19(16-25)$ & & $15(12-18)$ & & $4(3-6)$ & \\
\hline A little/Not at all & $31(19-36)$ & & $22(16-26)$ & & $8(4-10)$ & \\
\hline Do you consider yourself anxious? & & 0.001 & & 0.001 & & 0.001 \\
\hline Yes & $21.5(17-27)$ & & $16(12.5-20)$ & & $5(3-8)$ & \\
\hline No & $16(13-21)$ & & $13(10-16)$ & & $3(3-4.5)$ & \\
\hline $\begin{array}{l}\text { Are you anxious about your heart } \\
\text { rate disorder? }\end{array}$ & & 0.001 & & 0.001 & & 0.001 \\
\hline Very/Moderately & $25(18-31)$ & & $17(14-21)$ & & $6(3-9)$ & \\
\hline A little/Not at all & $18(14-23)$ & & $14(10-18)$ & & $3(3-6)$ & \\
\hline $\begin{array}{l}\text { Are you anxious about the proper } \\
\text { function of the device? }\end{array}$ & & 0.001 & & 0.001 & & 0.001 \\
\hline Very/Moderately & $25(18-31)$ & & $17(14-22)$ & & $6.5(3-9)$ & \\
\hline A little/Not at all & $18(14-23)$ & & $14(10-18)$ & & $3.5(3-6)$ & \\
\hline $\begin{array}{l}\text { Do you have someone who helps } \\
\text { you in your everyday activities? }\end{array}$ & & 0.001 & & 0.001 & & 0.001 \\
\hline Yes & $23(18-31)$ & & $16(14-21)$ & & $6(3-9)$ & \\
\hline No & $17(13-21)$ & & $13(10-18)$ & & $3(3-6)$ & \\
\hline $\begin{array}{l}\text { Do you think that the pacemaker } \\
\text { solves the problem of arrhythmia? }\end{array}$ & & 0.001 & & 0.001 & & 0.001 \\
\hline Yes & $19(15-26)$ & & $15(11-18)$ & & $4(3-8)$ & \\
\hline No & $36(33-38)$ & & $26.5(24-29)$ & & $9(9-9)$ & \\
\hline $\begin{array}{l}\text { Has your quality of life improved } \\
\text { after implantation? }\end{array}$ & & 0.001 & & 0.001 & & 0.001 \\
\hline Very much & $17.5(14-21)$ & & $14(10-16)$ & & $3(3-6)$ & \\
\hline Enough & $21(17-26)$ & & $16(13-20)$ & & $5(3-8)$ & \\
\hline A little/Not at all & $35(30-38)$ & & $26(22-28)$ & & $9(6.5-10)$ & \\
\hline Do you smoke after implantation? & & 0.012 & & 0.043 & & 0.001 \\
\hline Yes & $17(15-21)$ & & $13(11-16)$ & & $3(3-4)$ & \\
\hline No & $20(15-27)$ & & $15(11-20)$ & & $5(3-8)$ & \\
\hline $\begin{array}{l}\text { Do you exercise after } \\
\text { implantation? }\end{array}$ & & 0.001 & & 0.001 & & 0.001 \\
\hline Very much/Moderately & $15(11-21)$ & & $12(8-18)$ & & $3(3-4)$ & \\
\hline A little & $19(15-24)$ & & $15(11-16)$ & & $4(3-6)$ & \\
\hline Not at all & $24(17-33)$ & & $18(13-24)$ & & $7(3-9)$ & \\
\hline Parameter & $\begin{array}{l}\text { Spearman's } \\
\text { rho }\end{array}$ & $P$-value & $\begin{array}{l}\text { Spearman's } \\
\text { rho }\end{array}$ & $P$-value & $\begin{array}{l}\text { Spearman's } \\
\text { rho }\end{array}$ & $P$-value \\
\hline Age [years] & 0.248 & $<0.001$ & 0.266 & $<0.001$ & 0.176 & $<0.001$ \\
\hline Age when pacemaker was placed & 0.274 & $<0.001$ & 0.284 & $<0.001$ & 0.223 & $<0.001$ \\
\hline
\end{tabular}


report that their quality of life was improved (median: $35, p=0.001)$. Moreover, higher fatigue was felt by patients who did not smoke after the implantation and those who did not exercise at all (medians: 20 and 24, respectively). Lastly, a statistically significant positive association was found between fatigue and patients' age $(p<0.001)$ as well as between fatigue and patients' age after the pacemaker had been implanted $(p<0.001)$. Older patients felt more fatigue ( $r$ o $=0.248$ ) and the later the device was implanted the more fatigue the patients felt (rho $=0.274)$.

Similar associations were observed among patients' characteristics and physical as well as mental fatigue.

Convenience sampling is one of the principal limitations of this study. This method is not representative of all the population with a permanent cardiac pacemaker living in Greece, thus limiting the generalizability of the results. Other limitations are related to the study design, which was cross-sectional and not longitudinal, thus not permitting investigation for causal relations between fatigue and patients' characteristics.

Finally, there was no other test period that would allow evaluation of possible changes in fatigue levels over time.

\section{Discussion}

The results of the present study showed that the average age of the sample studied was 71 years and $64 \%$ of participants were male. Magnusson et al. [11] showed that median age of patients having an implanted pacemaker was 77.6 years and $57.0 \%$ were males.

Regarding levels of fatigue, participants experienced moderate to low levels of fatigue. Interestingly, the levels of energy increase immediately after implantation and recipients feel more capable physically due to improvements in symptoms. However, in the present study, the average age of participants was 71 years, which may partially explain the reduced energy levels.

In terms of type of pacemaker, $32 \%$ had a single chamber system (VVI) and 68\% had a dual chamber system (DDD). The research conducted by Magnusson et al. [11] showed that $76.6 \%$ of patients had a DDD pacemaker and $14.9 \%$ a VVI pacemaker. According to Toff et al. [12], the higher implantation rate of DDD pacemaker is attributed to their better emulation of cardiac physiology. It is noteworthy that the choice of pacing system seems to be associated with complications as Eberhardt et al. [5] indicated that implantation of DDD systems led to higher complication rates (6.3\%) than implantation of VVI (2.6\%). Irrespective of type of pacing, complications should be addressed carefully in a clinical setting as they require surgical interventions and extra follow-up visits and may aggravate already established fatigue [11].

The finding that women felt more fatigue is possibly attributed to their family care providing roles or to their tendency to experience stress more acutely than men. There are several concepts used to explain the fatigue in women. For example, female pacemaker recipients report more often pain, discomfort, and sleep disturbances. Additionally, due to the fact that they are generally smaller, they frequently report an impediment in arm movement [11]. Notably, women are older at implantation but have longer survival than men [13]. Moreover, they usually describe fatigue as living with a loss of physical energy, which in turn leads to dependency on others. However, women struggle to minimize their loss of independence [14].

Additionally, the results showed that patients who characterized themselves as anxious or were very anxious about their heart rate or the proper function of the device experienced more fatigue. Possibly, these participants may feel unable to handle their "new state in life" or their stressful feelings. Strikingly more, uncertainty in chronic illness is positively associated with tiredness and reduced functional status [15]. Pacemaker patients with high levels of anxiety feel more fatigue [16]. Psychosocial adjustment to the implanted device is fundamental. Adopting coping strategies, including focusing on activities, staying close to loved ones and having periods of rest, may relieve both the levels of fatigue and anxiety. Patient support groups that have frequent meetings where they exchange ideas, options and beliefs about the implanted device or therapy may be an alternative solution to combating anxiety. Ghojazadeh et al. [17] illustrated the need to reduce emotional and physical burden through rehabilitation, consultancy, support from family and hospital staff or other interventions. However, the present study showed that the majority of patients fulfilled social and family responsibilities.

According to the results, more fatigue was also experienced by participants with primary school education and those who were "a little or not at all" informed about the implanted device. Possibly, in their effort to learn how to live with the pacemaker, they experience various barriers due to ambiguities, inability to comprehend therapy or the available information [18]. Patients desire accurate information about the device provided by knowledgeable and helpful health care professionals who encourage them to take an active part in decision making [19]. Therefore, it is necessary to consider important caring aspects and develop interventions that address the needs of individuals living with a permanent cardiac pacemaker 
[20]. In the present study $41.2 \%$ reported needing written information.

More fatigue was felt by patients who did not think that their quality of life was improved. This finding refers to the patient's subjective viewpoint on his health and merits further research. De Barros et al. [21], who explored 107 patients after implantation of both genders (49.5\% women and $50.5 \%$ men) over 18 years old (average: 69.3 \pm 12.6 years), found that gender, age, and implantation time span influence quality of life and recommended considering these variables in strategies for improving quality of life.

Moreover, patients who did not exercise at all felt higher fatigue. The relationship between physical exercise and fatigue has received a great deal of attention during the last century but it is still not deeply understood. On the one hand, a chronic disease accelerates the depletion of energy stocks, while on the other hand, it establishes an exercise-avoiding behavior. This is presumed to be a mechanism to protect individuals from the exhaustion of energy levels and to enhance survival during disease [22]. Furthermore, patients usually adopt the false perception of avoiding participation in strenuous activities. In the majority of cases, a pacemaker does not limit participation in sports and exercise, apart from full-contact sports, such as football. Patients usually have misconceptions about pacemakers deriving from notions or outdated information, thus requiring further knowledge in all pacemaker areas to avoid common mistakes [23].

The present results showed that $78 \%$ of participants reported attending the routine device follow-up. This procedure is important in terms of patient benefits and safety of the pacing system. Duru et al. [24] reported that pacemaker patients attend the clinic every 9-12 months, so they are considered as not being closely linked with the clinic or not keen to cooperate for their own benefit. Udo et al. [25], who collected data in the period 2003-2010, regarding follow-up of 1517 patients with a first pacemaker implantation in 23 Dutch hospitals, found that $73 \%$ of patients with a single-chamber pacemaker had at least 1 follow-up/ year and $36 \%$ of patients with a dual chamber pacemaker had at least 2 follow-ups/year.

Another finding of this study concerned the use of a telephone. Specifically, $49.8 \%$ of participants reported not having limited the usage of a mobile phone. Electromagnetic interference may occur between cardiac pacemakers and wireless handheld telephones when carried on the same side of the implanted device. Patients who are aware of this potential problem when using the phone hold it at least $15 \mathrm{~cm}$ away from the pacemaker and on the opposite ear [26]. Future technology is expected to reshape pacemakers.
Finally, the results showed that older patients felt more fatigue and the later the device was implanted the more fatigue the patients felt. Permanent cardiac pacemaker implantation rates increase with age. According to estimates, 70-80\% of all types of pacemakers are implanted in patients 65 years of age or older. Taking for granted that the world's population is ageing at an alarming rate, pacemaker related issues in the elderly merit further research due to their clinical and socio-economic implications [27].

In conclusion, the present study revealed that fatigue was associated with age (older participants), gender (women), education level (primary school), level of information, age at implantation, existence of help in daily activities, and the $a b$ sence of smoking and exercise. Additionally, more fatigue was felt by participants who considered themselves anxious or were very anxious about their heart rate or the proper function of the device. Finally, fatigue was associated with patients' beliefs (did not believe that their life was improved and did not believe that the pacemaker solved the problem of arrhythmia).

It is widely known that fatigue is a subjective symptom that can adversely affect the outcome of the disease. Clinically, the present findings may foster recognition and early treatment of fatigue.

Hopefully, understanding which patient-related characteristics are associated with this distressing symptom will enhance individualized therapeutic treatment and enable meaningful research.

Future studies on fatigue measurements before and after implantation of a cardiac pacemaker as well as on the appropriate approach to the fatigued patient will shed more light on this symptom.

\section{Acknowledgments}

This study was a part of postdoctoral research conducted in the Department of Nursing, Faculty of Human Movement and Quality of Life Sciences, University of Peloponnese, Sparta Lakonias, Greece. We would like to express our gratitude to Georgios I. Panoutsopoulos for sharing his wisdom and his clinical expertise with us during the course of this research.

\section{Conflict of interest}

The authors declare no conflict of interest.

\section{References}

1. Kotsakou M, Kioumis I, Lazaridis G, et al. Pacemaker insertion. Ann Transl Med 2015; 3: 42.

2. Greenspon AJ, Patel JD, Lau E, et al. Trends in permanent pacemaker implantation in the United States from 1993 to 2009: increasing complexity of patients and procedures. J Am Coll Cardiol 2012; 60: 1540-5. 
3. Trohman RG, Kim MH, Pinski SL. Cardiac pacing: the state of the art. Lancet 2004; 364: 1701-19.

4. Pakarinen S, Oikarinen L, Toivonen L. Short-term implantation-related complications of cardiac rhythm management device therapy: a retrospective single-centre 1-year survey. Europace 2010; 12: 103-8.

5. Eberhardt F, Bode F, Bonnemeier $\mathrm{H}$, et al. Long term complications in single and dual chamber pacing are influenced by surgical experience and patient morbidity. Heart 2005; 91: 500-6.

6. Polyzos KA, Konstantelias AA, Falagas ME. Risk factors for cardiac implantable electronic device infection: a systematic review and meta-analysis. Europace 2015; 17: 767-77.

7. Johansen JB, Jørgensen OD, Møller M, Arnsbo P, Mortensen PT, Nielsen JC. Infection after pacemaker implantation: infection rates and risk factors associated with infection in a population based cohort study of 46299 consecutive patients. Eur Heart J 2011; 32: 991-8.

8. Swain MG. Fatigue in chronic disease. Clin Sci (Lond) 2000; 99: 1-8.

9. Craig T, Kakumanu S. Chronic fatigue syndrome: evaluation and treatment. Am Fam Physician 2002; 65: 1083-90.

10. Zyga S, Alikari V, Sachlas A, et al. Assessment of fatigue in end stage renal disease patients undergoing hemodialysis: prevalence and associated factors. Med Arh 2015; 69: 376-80.

11. Magnusson P, Liv P. Living with a pacemaker: patient-reported outcome of a pacemaker system. BMC Cardiovasc Disord 2018; 18: 110.

12. Toff WD, Camm AJ, Skehan JD. Single-chamber versus dual-chamber pacing for high-grade atrioventricular block. N Engl J Med 2005; 353: 145-55.

13. Brunner M, Olschewski M, Geibel A, Bode C, Zehender M. Long-term survival after pacemaker implantation: prognostic importance of gender and baseline patient characteristics. Eur Heart J 2004; 25: 88-95.

14. Hagglund L, Boman K, Lundman B. The experience of fatigue among elderly women with chronic heart failure. Eur J Cardiovasc Nurs 2008; 7: 290-5.

15. Falk K, Swedberg K, Gaston-Johanson F, Ekamn I. Fatigue is a prevalent and severe symptom associated with uncertainty and sense of coherence in patients with chronic heart failure. Eur J Cardiovasc Nurs 2007; 6: 99-104.

16. Polikandrioti M, Tzirogiannis K, Zyga S, et al. Effect of anxiety and depression on the fatigue of patients with permanent pacemaker. Arch Med Sci Atheroscler Dis 2018; 3: e8-17.

17. Ghojazadeh M, Azami Aghdash S, Sohrab Navi Z, Kolahdouzan K. Cardiovascular patients' experiences of living with pacemaker. ARYA Atheroscler 2015; 11: 281-8.

18. Gholami M, Fallahi Khoshknab M, Maddah SS, Ahmadi F, Khankeh H. Barriers to health information seeking in Iranian patients with cardiovascular disease: a qualitative study. Heart Lung 2014; 43: 183-91.

19. Adams RJ. Improving health outcomes with better patient understanding and education. Risk Manag Healthc Policy 2010; 3: 61-72.

20. Malm D, Karlsson JE, Fridlund B. 2007 Effects of a selfcare program on the health-related quality of life of pacemaker patients: a nursing intervention study. Can J Cardiovascular Nurs 2007; 17: 15-26.

21. De Barros RT, de Carvalho SMR, Silva MA de M, Borges JBC. Evaluation of patients' quality of life aspects after cardiac pacemaker implantation. Rev Bras Cir Cardiovasc 2014; 29: 37-44.

22. Ament W, Verkerke GJ. Exercise and fatigue. Sports Med 2009; 39: 389-422
23. Wood MA, Ellenbogen KA. Cardiology patient pages. Cardiac pacemakers from the patient's perspective. Circulation 2002; 105: 2136-8.

24. Duru F, Büchi S, Klaghofer R, et al. How different from pacemaker patients are recipients of implantable cardioverter-defibrillators with respect to psychosocial adaptation, affective disorders, and quality of life? Heart 2001; 85: 375-9.

25. Udo EO, vanZuihoff NO, Nijboer H, Doevendans PA, Moons KG. Long term quality-of-life in patients with bradycardia pacemaker implantation. Int I Cardiol 2013; 168: 2159-63.

26. Erdogan O. Electromagnetic interference on pacemakers. Indian Pacing Electrophysiol J 2002; 2: 74-8.

27. Bradshaw PJ, Stobie P, Knuiman MW, Briffa TG, Hobbs MST. Trends in the incidence and prevalence of cardiac pacemaker insertions in an ageing population. Open Heart 2014; 1: e000177. 